\title{
Multiple mechanical support modalities and cardiac transplantation in a young child with corrected transposition
}

\author{
Ronald K. Woods, MD, PhD, ${ }^{\mathrm{a}, \mathrm{b}}$ Robert A. Neibler, MD, ${ }^{\mathrm{a}, \mathrm{c}}$ Steven J. Kindel, MD, ${ }^{\mathrm{a}, \mathrm{d}}$ \\ Michael E. Mitchell, MD, ${ }^{\mathrm{a}, \mathrm{b}}$ James S. Tweddell, MD, ${ }^{\mathrm{e}}$ and Viktor Hraska, MD, PhD, ${ }^{\mathrm{a}, \mathrm{b}}$ Milwaukee, Wis, and \\ Cincinnati, Ohio
}

\footnotetext{
From the ${ }^{\mathrm{a} D i v i s i o n}$ of Pediatric Cardiothoracic Surgery, Department of Surgery, ${ }^{\mathrm{b}}$ Division of Pediatric Critical Care, Department of Pediatrics, and ${ }^{\mathrm{c}}$ Division of Pediatric Cardiology, Department of Pediatrics, Medical College of Wisconsin and Herma Heart Institute at Children's Hospital of Wisconsin, Milwaukee, Wis; ${ }^{\mathrm{d}}$ Division of Cardiothoracic Surgery, Department of Surgery, Cincinnati Children's Hospital and Medical Center, Cincinnati, Ohio; and the ${ }^{\mathrm{e}}$ Division of Cardiothoracic Surgery, Department of Surgery, University of Cincinnati, Cincinnati, Ohio.

Disclosures: Authors have nothing to disclose with regard to commercial support.

Received for publication Oct 17, 2017; revisions received Nov 10, 2017; accepted for publication Nov 19, 2017; available ahead of print Jan 11, 2018.

Address for reprints: Ronald K. Woods, MD, PhD, Herma Heart Institute and Children's Hospital of Wisconsin, 9000 W Wisconsin Ave, Milwaukee, WI 53226 (E-mail: RWoods@chw.org).

J Thorac Cardiovasc Surg 2018;155:e161-3

$0022-5223 / \$ 36.00$

Copyright (C) 2017 by The American Association for Thoracic Surgery

https://doi.org/10.1016/j.jtcvs.2017.11.080
}

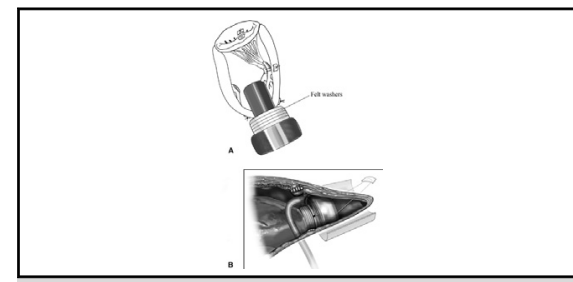

Modifications permitting placement of an intracorpor eal LVAD in a 13-kg patient.

Central Message

We present various technical modifications and modes of mechanical support, as well as cardiac transplantation in a young child with complex corrected transposition.

See Editorial Commentary page e165.

Video clip is available online.

We present a challenging case of a child with complex corrected transposition managed with various modes of mechanical support before and after cardiac transplantation.

\section{CASE SUMMARY}

Original anatomy was corrected transposition, situs inversus, left-sided inferior vena cava (IVC), ventricular septal defect, pulmonary valve atresia, and bilateral superior vena cavae without bridging vein. The child did well after a newborn shunt and Senning/Rastelli procedure at age 5 months. At age 4 years and a weight of $13 \mathrm{~kg}$, the child presented with medically refractory left ventricular (LV) systolic failure and mitral insufficiency, which led to placement of a continuous-flow left ventricular assist device (LVAD) (HVAD; HeartWare Inc, Framingham, Mass) and listing for cardiac transplantation. Technical modifications included (1) resection of an anomalous papillary muscle, papillary muscle sling, and edge-to-edge mitral repair; (2) external buttress felt rings $\times 5$ on the inflow sewing ring; and, importantly, (3) takedown of L diaphragmatic attachments, creation of sub-rectus pocket lined by $0.6-\mathrm{mm}$ polytetrafluoroethylene, and a number 6 polyester suture secured around the base of the pump and passed through the inferior apex of the pocket and tied external to the fascia (Figure 1). This ensured stable pump head and inflow cannula positioning. The outflow graft was restricted to $6 \mathrm{~mm}$. In addition, the pulmonary conduit was replaced, and the tricuspid valve was repaired. Excellent hemodynamic support was achieved. On postoperative day 9, we accepted a heart from a $39-\mathrm{kg}$ donor. The cross-match for our nonsensitized patient was negative.

For the heart transplant, the left pericardial attachments were taken down thoroughly to allow the apex of the heart to reside in the left chest. A modified biatrial technique was used-donor left atrium to recipient left atrium with the cuffs beveled for a leftward position of the heart; cuff of recipient morphologic right atrium tubularized and beveled to bring the left IVC to the right side; patch enlargement of the retained right atrial upper systemic venous island onto both superior vena cavae; and anastomosis of the right atrial superior venous island to the donor posterolateral right atrium (Figure 2).

Catheterization post-transplant day 4 to evaluate both respiratory and cardiac insufficiency (normal systolic function by echocardiogram) demonstrated a capillary wedge pressure of $25 \mathrm{~mm} \mathrm{Hg}$ and a biopsy negative for rejection (also donor-specific antibody negative). At repeat catheterization on day 21, LV end-diastolic pressure was $27 \mathrm{~mm} \mathrm{Hg}$, and biopsy was again negative for rejection. Cardiac arrest during this procedure led to extracorporeal membrane oxygenation support via the right neck. Failure to tolerate extracorporeal membrane oxygenation wean after 4 days 

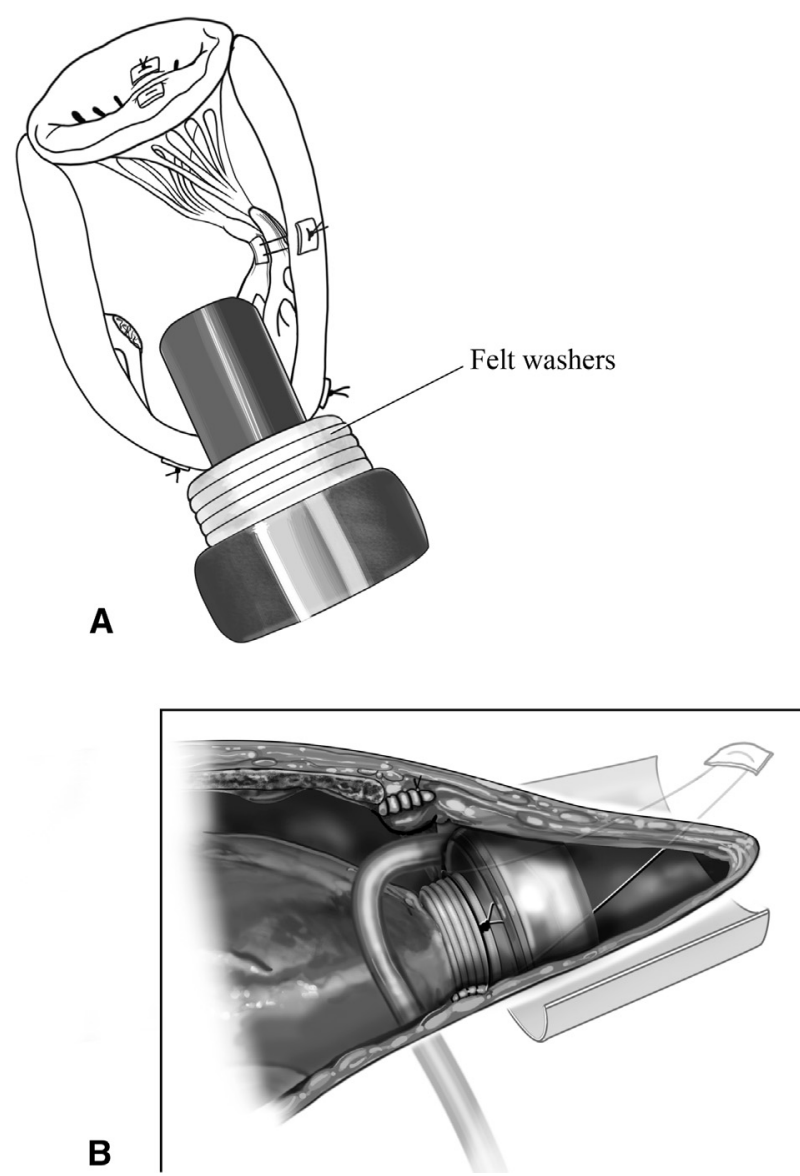

FIGURE 1. Technical modifications for LVAD placement: (A) resection of anomalous papillary muscle attached to the ventricular septum, papillary muscle sling, and edge-to-edge repair of the mitral valve; and (B) view from the right side of only the LV apex and pump head - creation of sub-rectus pocket lined with thick polyfluorotetraethylene and heavy suture around the pump head secured exterior to the rectus fascia at the inferior portion of the pocket to ensure stable and correct position of the inflow cannula.

of support led to conversion of mechanical support by placing a large-bore, straight-tip venous cannula and a $4 \mathrm{~F}$ pressure-monitoring line into the LV apex secured with double purse-string and short snares, creation of an LV to neck arterial cannula loop for LVAD support, and removal of the neck venous cannula (Figure 3 ). We did not alter the immunosuppression strategy. After 8 days, we observed consistent findings of an LV end-diastolic pressure of $8 \mathrm{~mm} \mathrm{Hg}$ with the LVAD flow stopped. The LVAD was removed with a simple procedure. Improvement was progressive, and ultimately the child was discharged to home 92 days after the initial HVAD placement and continues to do well as an outpatient at 7 months post-transplant.

\section{DISCUSSION}

This case illustrates the importance of adherence to basic principles and minor but creative technical modifications
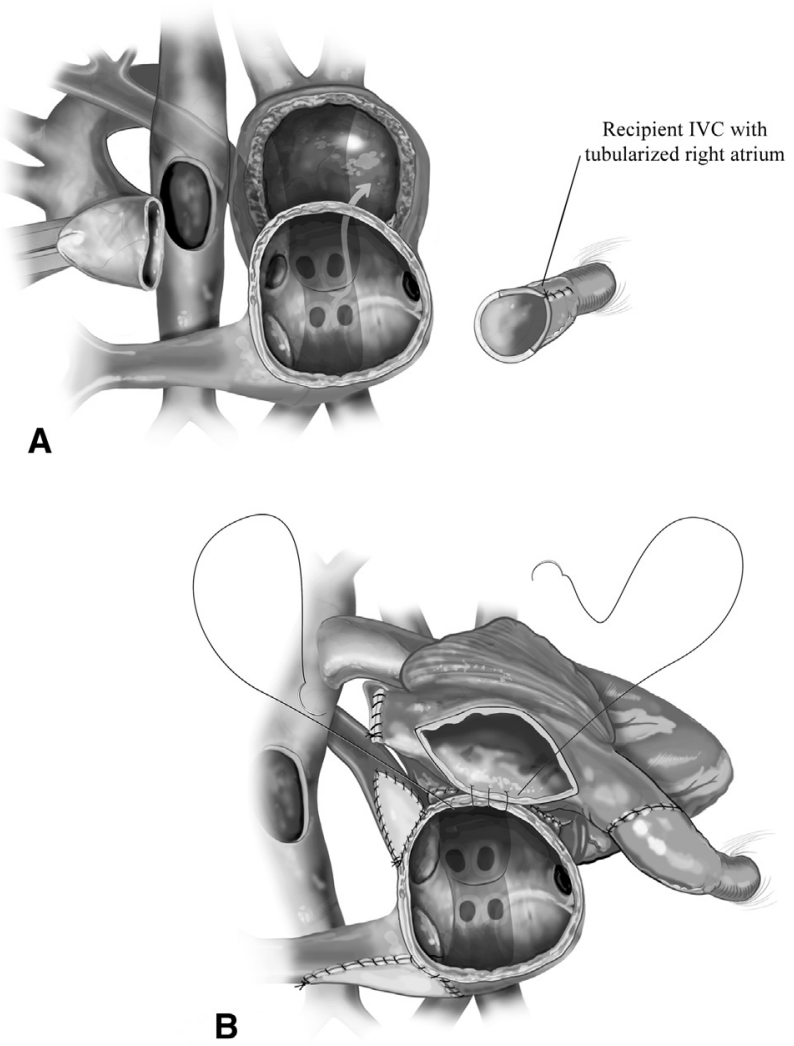

FIGURE 2. Technical modifications for the transplant: (A) recipient atrial cuffs and great vessels after explant of the recipient heart and pulmonary conduit (Senning pathway not well illustrated, atrial chamber on the anatomic left side received the pulmonary venous blood); and (B) left atrial anastomosis has been completed, IVC lengthened by tubularized recipient atrial tissue anastomosed to the donor IVC, patch enlargement of both superior vena cavae, and anastomosis of the superior systemic venous island of atrial tissue to the posterolateral donor right atrium with oversewing of donor superior vena cavae. $I V C$, Inferior vena cava.

that permitted salvage of a series of challenging clinical events. First, the HVAD can be placed in a small child with the technical modifications described (see Video 1). Others have described atrial cannulation and atrioventricular valve resection. ${ }^{1}$ We agree that the valve can be resected if necessary. In this case, we accomplished the same goal by resecting part of the subvalve apparatus and using a papillary muscle sling and edge-to-edge repair. Second, with corrected transposition and complex systemic venous anatomy, easily implemented technical maneuvers enable implantation of the heart in a levocardia position. ${ }^{2-}$

${ }^{4}$ In the patient post-Senning, both the systemic and pulmonary venous pathways should be widely patent because atrial pressures can change variably in the first few days and lead to compression of one of the pathways. Third, a minithoracotomy and apical cannulation with snares left in the chest provide an excellent short-term option for 


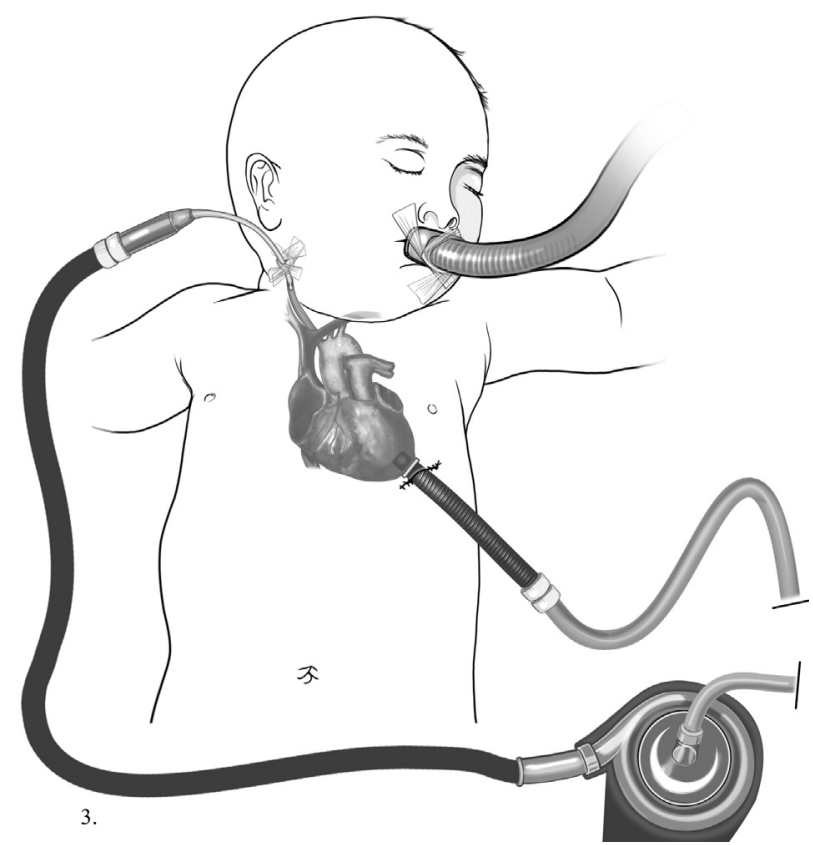

FIGURE 3. L mini-thoracotomy, limited sixth rib resection, and creation of LV apex to right carotid artery LVAD. This was done using double pursestrings in the LV apex with short snares and direct apical incision, serial dilation, and placement of a $19 \mathrm{~F}$ straight venous cannula into the $\mathrm{LV}$ while the patient was on extracorporeal membrane oxygenation support (flows decreased during apical cannulation). Snares were secured to the inflow cannula and placed inside the left chest, and the chest was closed. Extracorporeal membrane oxygenation support was stopped, and the de-aired LVAD tubing was connected to the right carotid cannula and LVAD flow initiated with echo monitoring. The LVAD pump was a ROTAFLOW (MAQUET Cardiovascular, LLC, Wayne, NJ). The neck venous line was removed, and the vein was repaired. Not shown is a $4 \mathrm{~F}$ pressure-monitoring line placed alongside the inflow cannula for real-time pressure monitoring.

LVAD support. The addition of an LV pressure-monitoring catheter provided real-time assessment of recovery and decision to decannulate. We recognize the debatable merit of accepting a donor offer after only 8 days of ventricular assist device support. Because our patient's end-organ function was good, we found it difficult to decline a donor organ with excellent function and a favorable immunologic profile.

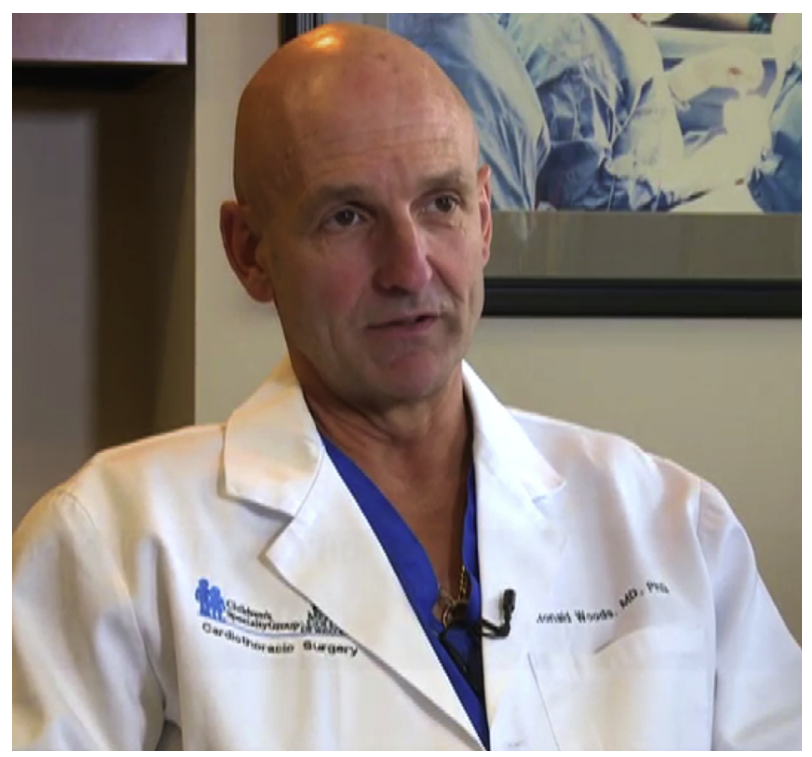

VIDEO 1. Dr Woods providing commentary on ventricular assist device support of small children. Video available at: http://www.jtcvsonline.org/ article/S0022-5223(17)32840-4/fulltext.

\section{CONCLUSIONS}

Creative modifications, while adhering to basic principles, permit a variety of modes of mechanical circulatory support to enable survival of children with heart failure and complex congenital heart disease.

The authors thank Jason Lavasseur for the medical illustrations.

\section{References}

1. Nandi D, Miller KD, Bober CM, Rosenthal TM, Montenegro LM, Rossano JW et al. Systemic atrioventricular valve excision and ventricular assist devices in pediatric patients. Ann Thorac Surg. 2018;105:170-4.

2. Vricella LA, Razzouk AJ, Gundry SR, Larsen RL, Kuhn MA, Bailey LL. Heart transplantation in infants and children with situs inversus. J Thorac Cardiovasc Surg. 1998;116:82-9.

3. Young BAC, Nealy ZB, McGrath MF, Herre JM. Orthotopic heart transplant following implantation of a systemic ventricular assist device in a patient with congenitally corrected transposition of the great arteries and dextrocardia situs inversus totalis. VAD J. 2016; https://doi.org/10.13023/VAD.2016.09:1-9.

4. Raisky O, Tamisier D, Vouhe PR. Orthotopic heart transplantation for congenital heart defects: situs inversus. Multimed Man Cardiothorac Surg. 2006;2006 mmcts.2005.001586. 